\title{
PRESENCIA DE HONGOS EN EL AIRE DE AULAS DEL DEPARTAMENTO DE INGENIERÍA QUÍMICA Y METALURGIA DE LA UNIVERSIDAD DE SONORA, UNIDAD CENTRO
}

\author{
Presence of fungi in the air inside the classrooms at the department of chemical \\ engineering and metallurgy of the university of sonora, unit center
}

EPISTEMUS

ISSN: 2007-8196 (electrónico)

ISSN: 2007-4530 (impresa)

Gilberto García Navarrete ${ }^{1}$

Griselda Adilene Sánchez Cubedo ${ }^{2}$

Sylvia Lorenia López Mazón ${ }^{3}$

María Elena Ochoa Landín 4

Virgilio Rubio Nieblas 5

Recibido: 18 de marzo de 2016 , Aceptado: 31 de mayo del 2016

Autor de Correspondencia: M. C. Gilberto García Navarrete

Correo: ggarcian@iq.uson.mx

\section{Resumen}

En este trabajo se evaluó la presencia de hongos en el aire de aulas del Departamento de Ingeniería Química y Metalurgia, recolectándose 90 muestras utilizando el método pasivo en cajas Petri de $90 \mathrm{~mm}$ de diámetro, que contenían Agar Sabouraud Dextrosa. Para identificar el tipo de hongo se preparó un frotis, de acuerdo a la técnica de Impronta. Se determinó la forma y ordenamiento característico de las esporas.

Los hongos encontrados fueron Alternaria sp., Aspergillus flavus, Aspergillus niger, Cladosporium sp., Drechslera sp., Penicillium sp., y Fusarium sp. De acuerdo al número de unidades formadoras de colonias (UFC) registradas durante los días de monitoreo, los mayores recuentos se encontraron en el turno matutino, antes del inicio de actividades. Además, se observó que el muestreo matutino del día Lunes presentó la mayor cantidad de UFC en las diferentes aulas, lo cual se atribuye principalmente a la inactividad en el fin de semana.

Palabras clave: hongos, esporas, UFC.

\section{Abstract}

This article evaluates the presence of fungi in the air inside the classrooms at the Department of Chemical Engineering and Metallurgy. Ninety samples were collected using the passive method in Petri dishes, containing Sabouraud dextrose agar. An imprint smear was prepared to identify the type of fungus. Characteristic shape and arrangement of spores was determined.

Fungi found include Alternaria sp., Aspergillus flavus, Aspergillus niger, Cladosporium sp., Drechslera sp., Penicillium sp. and Fusarium sp. According to the number of colony-forming units (CFU) registered during the monitoring days, the highest fungal counts were found in the morning shift, before activities began. Additionally, it was observed that the morning sampling performed on Monday showed the highest number of CFU in different classrooms, due mainly to the inactivity of the weekend.

Keywords: Fungi, spores, CFU.

1 Depto. de Ingeniería Química y Metalurgia, Universidad de Sonora / Correo: ggarcian@iq.uson.mx 2 Depto. de Ingeniería Química y Metalurgia, Universidad de Sonora 3 Depto. de Ingeniería Química y Metalurgia, Universidad de Sonora / Correo: sllopez@iq.uson.mx 4 Depto. de Ingeniería Química y Metalurgia, Universidad de Sonora / Correo: meochoa@iq.uson.mx 5 Depto. de Ingeniería Química y Metalurgia, Universidad de Sonora / Correo: virgil@iq.uson.mx 


\section{INTRODUCCIÓN}

La contaminación del aire interior se caracteriza por una gran variedad de concentración de contaminantes en diferentes ambientes interiores, variando espacial y temporalmente. Entre otros factores tenemos el comportamiento de los ocupantes del espacio pero también las condiciones de ventilación [1]. La supervivencia, reproducción y dispersión hacia el aire de los contaminantes biológicos dependen, en gran medida, de las condiciones del entorno en que se encuentran. Factores tales como la temperatura, la humedad relativa, el movimiento del aire, la luz y las fuentes de alimento, van a determinar el grado en que los contaminantes biológicos se encontrarán en un ambiente [2].

Los hongos representan un creciente problema en nuestra sociedad como organismos contaminantes en superficies interiores de los edificios y como patógenos para la salud humana [3]. Los problemas asociados con la calidad del aire interior se relacionan con los hongos ya que los resultados de análisis micológico de aire, realizados en edificios de varios países han demostraron que los hongos representan alrededor del $70 \%$ de la contaminación microbiana del aire interior, es decir, la contaminación biológica del aire interior es ocasionada principalmente por hongos, incluyendo a los hongos filamentosos y a las levaduras [4]. Dados los riesgos que los hongos representan, se han realizado varias investigaciones relacionadas con ellos y el contacto que los seres humanos puedan tener con los mismos. Diversos estudios han reportado que la contaminación del aire interior de los espacios escolares puede aumentar, a largo y corto plazo, los problemas de salud en los estudiantes y profesores en lo que respecta al confort, la productividad y desempeño académico $[1,5]$.

En una investigación se evaluó la calidad microbiológica del aire interior en aulas de edificios de universidades seleccionados en el centro de Poznan, Polonia, donde miles de personas permanecen varias horas estudiando y trabajando en áreas cerradas todos los días y donde la calidad del aire puede influenciar su salud y condición física [6]. Además, en Wroclaw, Polonia se realizó una investigación para evaluar el grado de contaminación micológica del aire en habitaciones de albergues de estudiantes [4].

En un trabajo de sedimentación en placa para determinar la presencia de hongos en ambientes de bibliotecas de la Universidad de Carabobo en Valencia Venezuela se encontraron con mayor frecuencia Geotrichum sp., Cladosporium sp., Aspergillus sp., Circinella $s p$. y Zigomicetes tanto en ambiente como en libros. La temperatura y humedad relativa promedios durante este estudio fueron de $26.6^{\circ} \mathrm{C}$ y $57.06 \%$ respectivamente [7]. Por otra parte, en una investigación realizada en el ambiente de 15 bibliotecas de la Universidad Autónoma de Sinaloa fueron identificadas las cepas de 11 géneros de hongos, entre los que tenemos: Rhizopus., Fusarium, Bipolaris, Aspergillus, Alternaria, Curvularia, Penicillium,
Aerobasidium, Stemphylium, Cladosporium y Mucor [8].

Existe mucha variabilidad para establecer un estándar de calidad microbiológica del aire. En Suecia hasta 500 $\mathrm{UFC} / \mathrm{m}^{3}$ para bacterias y de $300 \mathrm{UFC} / \mathrm{m}^{3}$ para esporas fúngicas puede ser aceptable en ambientes interiores. Sin embargo, en 2001, la Asociación Americana de Higiene Industrial (AlHA) publicó una propuesta de directrices para la cantidad de esporas de hongos en diferentes ambientes interiores, por ejemplo, edificios residenciales y comerciales. La guía para los edificios residenciales son menos de 500 $\mathrm{UFC} / \mathrm{m}^{3}$ y para edificios comerciales menos de $250 \mathrm{UFC} / \mathrm{m}^{3}$. En Brasil la concentración de microorganismos en el aire (especialmente hongos) en lugares cerrados no debe ser superior a $750 \mathrm{UFC} / \mathrm{m}^{3}$. En Hong Kong una buena calidad microbiológica del aire debe tener menos de $1000 \mathrm{UFC} / \mathrm{m}^{3}$ de bacterias. Si se incluye menos de $500 \mathrm{UFC} / \mathrm{m}^{3}$, el aire se clasifica como excelente. En Singapur, los requisitos para la calidad del aire interior establecen concentraciones de bacterias en el nivel máximo de $500 \mathrm{UFC} / \mathrm{m}^{3}[6]$.

El objetivo del presente trabajo fue evaluar la presencia de hongos en ocho aulas del Departamento de Ingeniería Química y Metalurgia de la Universidad de Sonora durante los meses de noviembre y diciembre de 2014.

\section{METODOLOGÍA}

Las aulas consideradas en este estudio fueron ocho de las nueve aulas del Departamento de Ingeniería Química y Metalurgia de la Unidad Centro en los edificios 5E (planta alta y baja) y $5 \mathrm{I}$ (planta alta); la figura 1 muestra el aspecto general de una de estas aulas, mientras que en la tabla 1 se presenta un resumen descriptivo de las mismas.

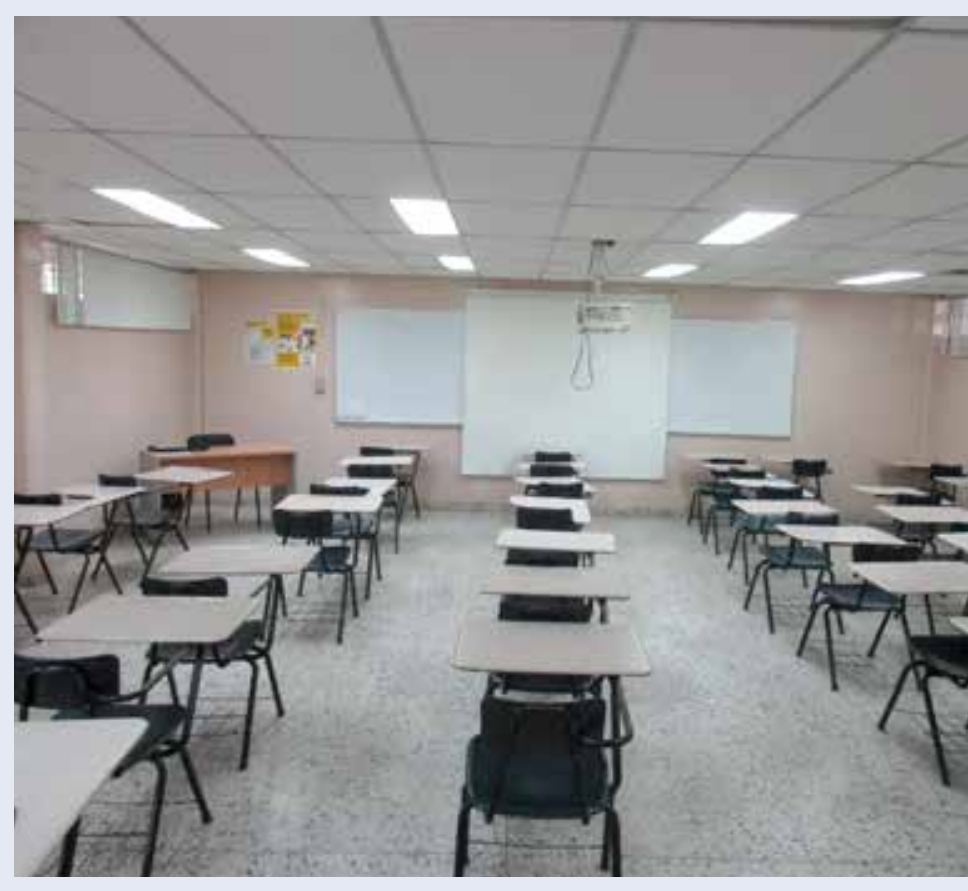

Figura 1. Aspecto general de una de las aulas del estudio. 
Tabla 1. Descripción general de las aulas del estudio.

\begin{tabular}{|c|c|c|c|c|c|c|c|c|}
\hline AULA & 5E-101 & 5E-102 & 5E-103 & 5E-201 & $5 E-202$ & $5 \mid-201$ & $5 \mid-202$ & $5 \mid-203$ \\
\hline $\begin{array}{l}\text { Alumnos } \\
\text { por aula }\end{array}$ & 40 & 40 & 40 & 35 & 35 & 40 & 30 & 30 \\
\hline \multicolumn{9}{|c|}{ Capacidades } \\
\hline Superficie $\left(\mathrm{m}^{2}\right)$ & 72.95 & 72.95 & 72.95 & 48.27 & 48.27 & 49.2 & 35.93 & 35.93 \\
\hline Volumen $\left(\mathrm{m}^{3}\right)$ & 175.80 & 175.80 & 175.80 & 128.87 & 128.87 & 138.75 & 101.31 & 101.31 \\
\hline $\mathrm{m}^{2}$ por alumno & 1.82 & 1.82 & 1.82 & 1.38 & 1.38 & $1.23^{\Delta}$ & $1.20^{\Delta}$ & $1.20^{\Delta}$ \\
\hline \multicolumn{9}{|c|}{ Aire acondicionado } \\
\hline Minisplit & (2) 2 ton $\mathrm{c} / \mathrm{u}$ & (2) 2 ton $\mathrm{c} / \mathrm{u}$ & (2) 2 ton $\mathrm{c} / \mathrm{u}$ & (2) 2 ton $\mathrm{c} / \mathrm{u}$ & (2) 2 ton $\mathrm{c} / \mathrm{u}$ & (1) 4 ton $\mathrm{c} / \mathrm{u}$ & (1) 4 ton $\mathrm{c} / \mathrm{u}$ & (1) 4 ton $\mathrm{c} / \mathrm{u}$ \\
\hline $\begin{array}{l}\text { Superficie } \\
\text { ventanas }\left(\mathrm{m}^{2}\right)\end{array}$ & 2.85 & 2.85 & 2.85 & 2.88 & 2.88 & 3.01 & 1.07 & 1.98 \\
\hline \multicolumn{9}{|c|}{ Extracción y ventilación mecánica } \\
\hline Equipo & No & No & No & No & No & No & No & No \\
\hline $\begin{array}{l}\text { Recambio de } \\
\text { aire por hora }\end{array}$ & $\begin{array}{c}6.5 \text { veces } \\
\text { volumen } \\
\text { aula }\end{array}$ & $\begin{array}{c}6.5 \text { veces } \\
\text { volumen } \\
\text { aula }\end{array}$ & $\begin{array}{c}6.5 \text { veces } \\
\text { volumen } \\
\text { aula }\end{array}$ & $\begin{array}{c}7.8 \text { veces } \\
\text { volumen } \\
\text { aula }\end{array}$ & $\begin{array}{c}7.8 \text { veces } \\
\text { volumen } \\
\text { aula }\end{array}$ & $\begin{array}{c}8.3 \text { veces } \\
\text { volumen } \\
\text { aula }\end{array}$ & $\begin{array}{c}8.5 \text { veces } \\
\text { volumen } \\
\text { aula }\end{array}$ & $\begin{array}{c}8.5 \text { veces } \\
\text { volumen } \\
\text { aula }\end{array}$ \\
\hline \multicolumn{9}{|c|}{ Iluminación } \\
\hline Focos & $\begin{array}{l}12 \text { de neón } \\
\text { de } 28 \text { watt }\end{array}$ & $\begin{array}{l}12 \text { de neón } \\
\text { de } 28 \text { watt }\end{array}$ & $\begin{array}{l}12 \text { de neón } \\
\text { de } 28 \text { watt }\end{array}$ & $\begin{array}{l}12 \text { de neón } \\
\text { de } 28 \text { watt }\end{array}$ & $\begin{array}{l}12 \text { de neón } \\
\text { de } 28 \text { watt }\end{array}$ & $\begin{array}{l}8 \text { de neón } \\
\text { de } 28 \text { watt }\end{array}$ & $\begin{array}{l}8 \text { de neón } \\
\text { de } 28 \text { watt }\end{array}$ & $\begin{array}{l}6 \text { de neón } \\
\text { de } 28 \text { watt }\end{array}$ \\
\hline
\end{tabular}

Fuente: Departamento de Ingeniería Química y Metalurgia y levantamiento de campo.

${ }^{\Delta}$ Por debajo de lo que establece el Instituto Nacional de la Infraestructura Física Educativa (INIFED) para escuelas de media superior 1.35 $\mathrm{m}^{2} /$ alumno.

- Estimado a partir del volumen total del aula, número de alumnos y el requerimiento de ventilación por persona de 8 L/s (28.8 m3/h) establecido por la ASHRAE [9] para un aula de clase.

Días previos al análisis se prepararon cajas de Petri conteniendo medio de cultivo agar Sabouraud marca Difco, las cuales se expusieron a temperatura ambiente de 15 a 20 minutos antes de llevar a cabo el muestreo. La recolección de muestras en las aulas se realizó mediante el método pasivo, durante los días de actividad académica. Se colocó una caja Petri en el centro de cada aula durante cinco días de diferentes semanas tanto en la mañana como en la tarde. El tiempo de exposición de las cajas Petri con el medio fue de 30 minutos a una altura de $1.0 \mathrm{~m}$. Pasado el tiempo de exposición, se recolectaron las diferentes cajas, tapándolas cuidadosamente y llevándolas a una incubadora marca Felisa Modelo 132, misma que estaba a una temperatura de $28^{\circ} \mathrm{C}$.

Diariamente, se monitoreó el crecimiento fúngico en las placas y se contaron las unidades formadoras de colonias (UFC) en cada placa. Alrededor del tercer o cuarto día, el tamaño de los hongos fue el apropiado para poder realizar frotis. Los frotis se observaron con un microscopio óptico marca Leica Modelo CME para diferenciar la forma y ordenamiento característico de las esporas, considerando los aspectos distintivos contenidos en la tabla 2 [10]. 
Tabla 2. Características distintivas de algunos hongos [10].

\begin{tabular}{|l|l|l|l|}
\hline \multicolumn{1}{|c|}{ Hongo } & \multicolumn{1}{|c|}{ Color y tonalidad de colonias } & \multicolumn{1}{c|}{ Forma } & \multicolumn{1}{c|}{ Estructura } \\
\hline Alternaria sp. & $\begin{array}{l}\text { Marrón-gris oscuras o verdes a } \\
\text { negras }\end{array}$ & $\begin{array}{l}\text { Los conidios tienen tabiques } \\
\text { horizontales y longitudinales }\end{array}$ & $\begin{array}{l}\text { Los conidios aparecen en cadenas } \\
\text { tienen un color marrón dorado }\end{array}$ \\
\hline Aspergillus flavus & $\begin{array}{l}\text { Habitualmente amarillas o } \\
\text { amarillo-verdes }\end{array}$ & $\begin{array}{l}\text { Vesículas redondas, esporulación } \\
\text { en toda la superficie }\end{array}$ & $\begin{array}{l}\text { Puede haber fiálides solas o con } \\
\text { métulas (biseriado) }\end{array}$ \\
\hline Aspergillus niger & Negras & Vesículas esféricas & $\begin{array}{l}\text { Biseriado-métulas grandes y } \\
\text { fiálides más pequeñas }\end{array}$ \\
\hline Cladosporium sp. & $\begin{array}{l}\text { Tonalidad oscura verde oliva, } \\
\text { gris o marrón }\end{array}$ & $\begin{array}{l}\text { Conidios elípticos. Algunos tienen forma } \\
\text { de escudo debido a los disyuntores } \\
\text { (cicatrices) }\end{array}$ & Conidios en cadena \\
\hline Drechshlera sp. & $\begin{array}{l}\text { Marrón negruzco similar a } \\
\text { Alternaria sp. }\end{array}$ & $\begin{array}{l}\text { Sus conidios son cilíndricos de } \\
\text { paredes lisas, separados por tabiques } \\
\text { transversales en 4 o más células, } \\
\text { redondeados en los extremos }\end{array}$ & Los conidióforos están retorcidos \\
\hline Fusarium sp. & $\begin{array}{l}\text { Propensión a producir pigmentos } \\
\text { color lavanda, púrpura o rojo- } \\
\text { rosado }\end{array}$ & $\begin{array}{l}\text { Las macroconidias son cilíndricas, } \\
\text { multicelulares y con forma de hoz }\end{array}$ & $\begin{array}{l}\text { Presencia de macroconidias y } \\
\text { también de microconidias en los } \\
\text { mismos aislamientos }\end{array}$ \\
\hline Penicillium sp. & $\begin{array}{l}\text { Habitualmente se observan } \\
\text { tonalidades de verde, azul-verde } \\
\text { o verde marrón. Puede haber } \\
\text { colonias amarillas y marrones }\end{array}$ & $\begin{array}{l}\text { La superficie de la colonia es } \\
\text { aterciopelada a pulverulenta. Las } \\
\text { cabezas de las colonias parecen cepillos } \\
\text { o dedos }\end{array}$ & $\begin{array}{l}\text { Fiálides con extremos romos que } \\
\text { dan origen a cadenas de conidias }\end{array}$ \\
\hline
\end{tabular}

\section{RESULTADOS Y DISCUSIÓN}

Los hongos identificados en el monitoreo del aire interior de las aulas del Departamento de Ingeniería Química y Metalurgia fueron los que se presentan en la figura 2. La temperatura durante el monitoreo matutino varió de $5.35^{\circ} \mathrm{C}$ a $17.19^{\circ} \mathrm{C}$, mientras que en el monitoreo vespertino se tuvieron temperaturas entre $24.78^{\circ} \mathrm{C}$ y $32.94^{\circ} \mathrm{C}$. La humedad relativa por su parte fluctuó de $41.4 \%$ a $100 \%$ en el monitoreo matutino y de $7.98 \%$ a $52.36 \%$ en el vespertino.

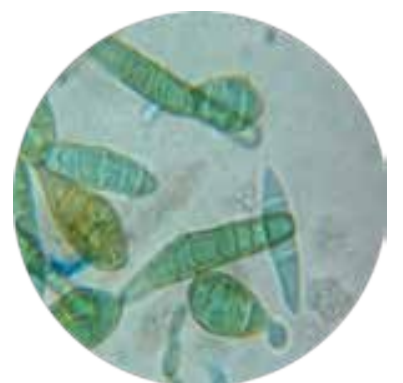

Alternaria sp.

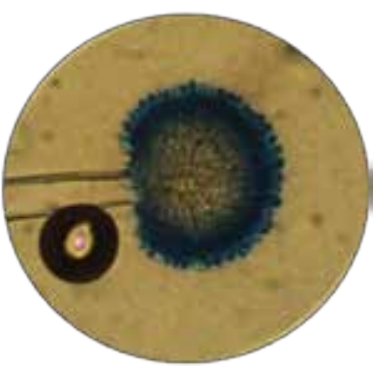

Aspergillus niger

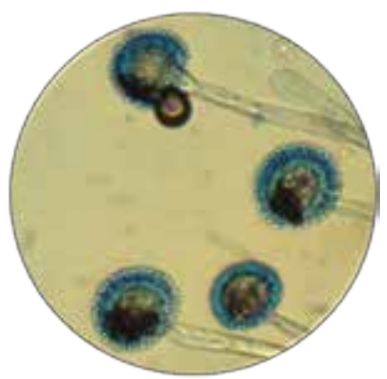

Aspergillus flavus

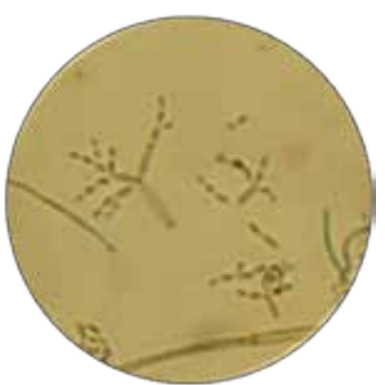

Cladosporium sp.

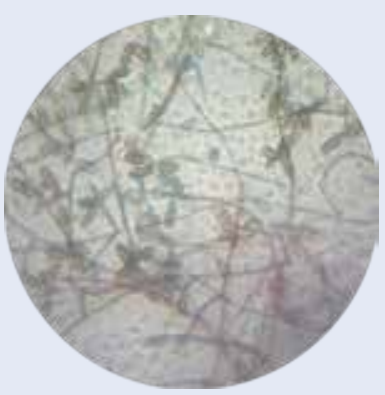

Drechslera sp.

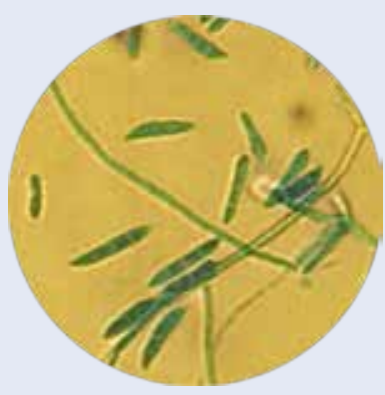

Fusarium sp.

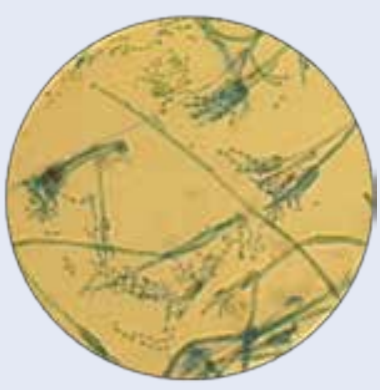

Penicillium sp.

Figura 2. Hongos identificados en el aire interior de las aulas del Departamento de Ingeniería Química y Metalurgia.

Para evaluar el comportamiento de cada aula durante el monitoreo matutino y vespertino se presentan las figuras 3 y 4 respectivamente. 


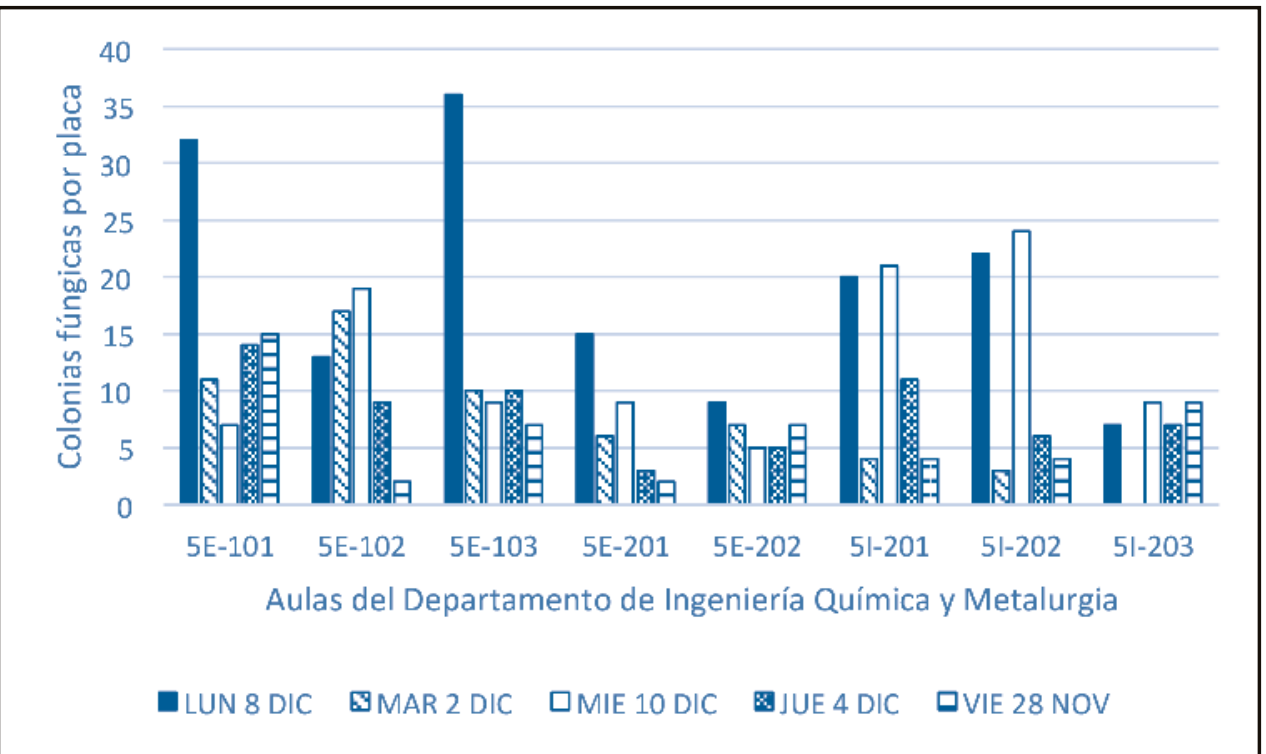

Figura 3. Colonias fúngicas por placa durante el monitoreo matutino.

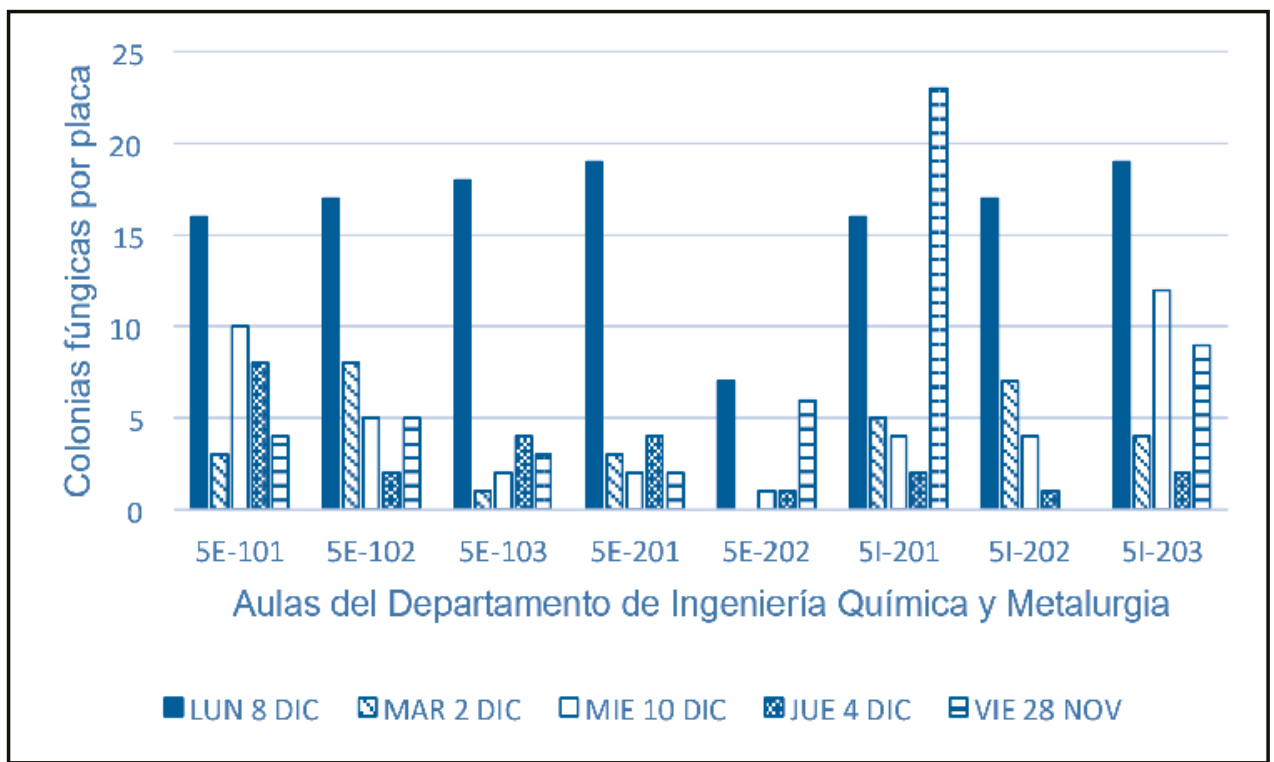

Figura 4. Colonias fúngicas por placa durante el monitoreo vespertino.

En la figura 3 que corresponde al registro de colonias fúngicas durante el monitoreo matutino se presentan valores de conteo mayores para el día lunes 8 de diciembre en las aulas $5 \mathrm{E}-101,5 \mathrm{E}-103,5 \mathrm{E}-201$ y $5 \mathrm{E}-202$. Los mayores conteos en el aula $5 \mathrm{E}-102$ se realizaron el miércoles 10 y martes 2 de diciembre con valores de 19 y 17, respectivamente, los cuales no están muy alejados de la cantidad obtenida para el día lunes 8 de diciembre de 2013. En las tres aulas del edificio $5 \mathrm{I}$ se presentó un comportamiento similar con los mayores valores el día miércoles 10 de diciembre aunque no muy alejados de los valores del día lunes 8 de diciembre.

De acuerdo a la figura 4 los registros durante el monitoreo vespertino fueron mayores el día lunes 8 de diciembre en todas las aulas excepto en la 5I-201, obteniéndose para el día viernes 28 de noviembre un conteo de 23 UFC mientras que para el lunes 8 de diciembre fue de 16. 


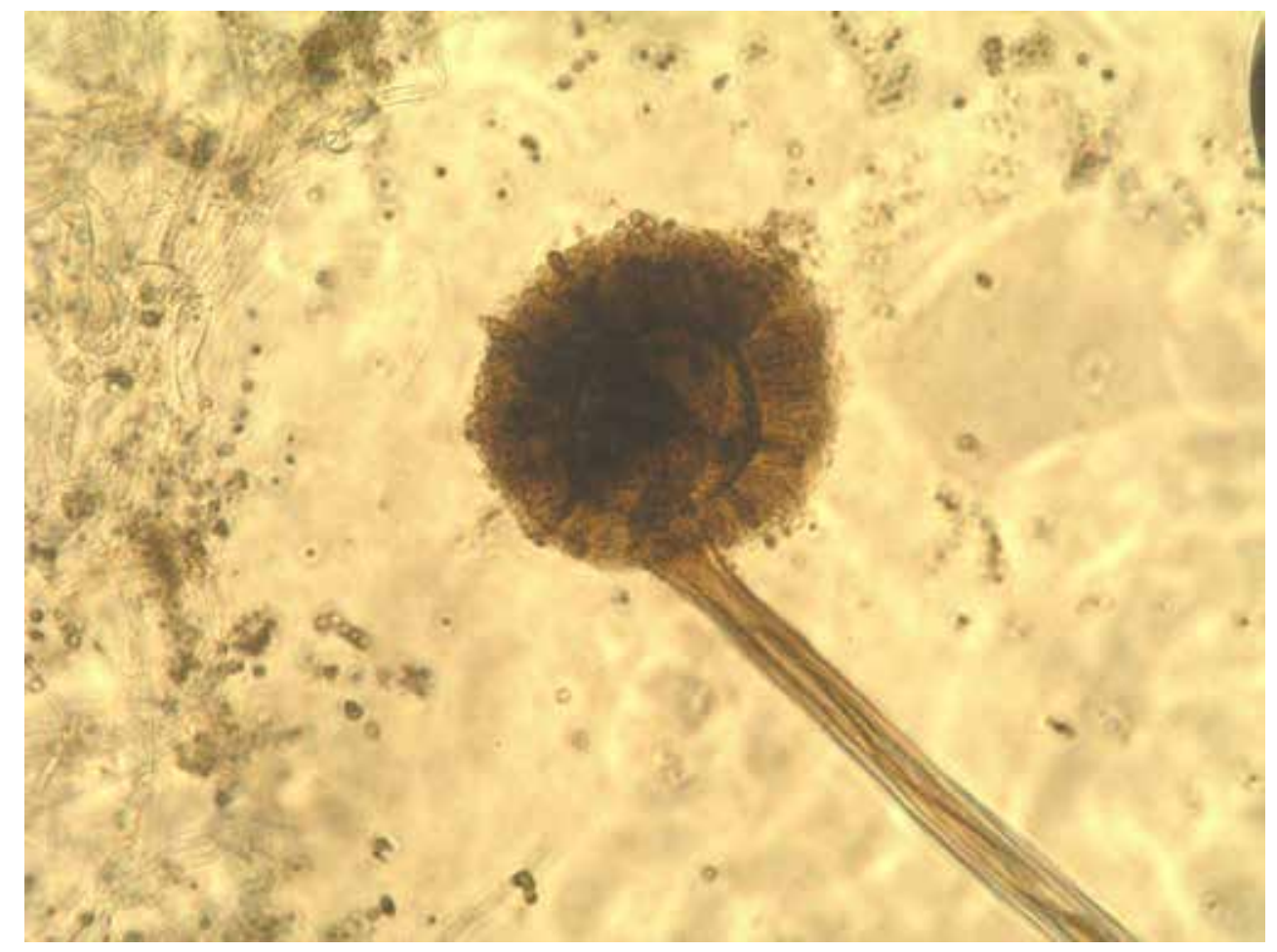

En la tabla 3 se presenta la concentración de microorganismos expresada como $\mathrm{UFC} / \mathrm{m}^{3}$, estimada de acuerdo a la ecuación [6]:

$$
\frac{U F C}{m^{3}}=\frac{10000 a}{0.2 p t}
$$

Donde:

$a$ - número de colonias en la caja Petri.

$p$ - área de la caja Petri, $\mathrm{cm}^{2}$.

$t$ - tiempo de exposición de la caja Petri.

Tabla 3. Concentración de esporas fúngicas, UFC/m³ .

\begin{tabular}{|c|c|c|c|c|c|c|c|c|c|c|}
\hline Fecha & \multicolumn{2}{|c|}{$\mathbf{2 8 - n o v - 1 4}$} & \multicolumn{2}{c|}{ 02-dic-14 } & \multicolumn{2}{c|}{ 04-dic-14 } & \multicolumn{2}{c|}{ 08-dic-14 } & \multicolumn{2}{c|}{ 10-dic-14 } \\
\hline Día de la semana & \multicolumn{2}{|c|}{ Viernes } & \multicolumn{2}{c|}{ Martes } & \multicolumn{2}{c|}{ Jueves } & \multicolumn{2}{|c|}{ Lunes } & \multicolumn{2}{c|}{ Miércoles } \\
\hline Aula/Turno & $\mathbf{M}$ & $\mathbf{V}$ & $\mathbf{M}$ & $\mathbf{V}$ & $\mathbf{M}$ & $\mathbf{V}$ & $\mathbf{M}$ & $\mathbf{V}$ & $\mathbf{M}$ & $\mathbf{V}$ \\
\hline $5 \mathrm{E}-101$ & 393 & 105 & 288 & 79 & 367 & 210 & 838 & 419 & 183 & 262 \\
\hline $5 \mathrm{E}-102$ & 52 & 131 & 445 & 210 & 236 & 52 & 341 & 445 & 498 & 131 \\
\hline $5 \mathrm{E}-103$ & 183 & 79 & 262 & 26 & 262 & 105 & 943 & 471 & 236 & 52 \\
\hline $5 \mathrm{E}-201$ & 52 & 52 & 157 & 79 & 79 & 105 & 393 & 498 & 236 & 52 \\
\hline $5 \mathrm{E}-202$ & 183 & 157 & 183 & 0 & 131 & 26 & 236 & 183 & 131 & 26 \\
\hline $5 \mathrm{I}-201$ & 105 & 602 & 105 & 131 & 11 & 52 & 524 & 419 & 550 & 105 \\
\hline $5 \mathrm{I}-202$ & 105 & 0 & 79 & 183 & 157 & 26 & 576 & 445 & 629 & 105 \\
\hline $5 \mathrm{I}-203$ & 236 & 236 & 131 & 105 & 183 & 52 & 183 & 498 & 236 & 314 \\
\hline
\end{tabular}

$p=63.63 \mathrm{~cm}^{2} . t=30$ minutos. 


\section{CONCLUSIONES Y RECOMENDACIONES}

Los géneros encontrados son los que típicamente se encuentran en el aire interior de sitios similares, son oportunistas y generan toxinas que pueden afectar la salud del ser humano.

De acuerdo a la diversidad de estándares para la calidad microbiológica del aire y a las concentraciones estimadas, es posible concluir que con respecto a la Asociación Americana de Higiene Industrial (AIHA) se estaría por encima del límite para edificios comerciales de 250 UFC/ $\mathrm{m}^{3}$. Mientras que de acuerdo a otras especificaciones se está dentro de los límites de buena calidad del aire entre 500 y $1000 \mathrm{UFC} / \mathrm{m}^{3}$.

Durante los días de monitoreo, la mayor concentración de hongos se encontró en general en el turno matutino, antes del inicio de actividades. La mayoría de las aulas presentó mayores registros fúngicos el día lunes 8 tanto en el monitoreo matutino como en el vespertino. Lo anterior se atribuye principalmente por la inactividad que se tiene por los fines de semana y la falta de ventilación adecuada.

Existen varios factores que no fueron posible controlar como fue el caso de la permanencia de aulas abiertas o cerradas (políticas de control de bienes en las aulas) en los intervalos entre clase y clase, además del transporte fúngico por parte de alumnos. Esto último además de influir en el conteo de hongos, también hizo muy variable los requerimientos de recambios de aire por aula. Para este estudio varió de 6.5 a 8.5 veces el volumen del aula en una hora de acuerdo a la capacidad máxima de alumnos reportada.

Es conveniente hacer notar que el muestreo abarcó parte del periodo de evaluaciones ordinarias, aunque en algunas aulas se seguían impartiendo clases, por lo que el comportamiento de actividad y limpieza de las aulas fueron factores importantes a tomar en cuenta en posteriores estudios. Por esto se recomiendan investigar mejores diseños de las instalaciones escolares, instalando y mejorando los sistemas de extracción y ventilación que permitan realizar los recambios de aires requeridos para instalaciones cerradas.

\section{BIBLIOGRAFÍA}

[1] De Gennaro, G., Rosario, D. P., Demarinis, L., Di Gilio, A., Giungato, P., Tutino, M., Marzocca, A., Mazzone, A., Palmisani, J. \& Porcelli, F. "Indoor Air Quality in Schools". Environmental Chemistry Letters. Vol. 12, p. 467-482. 2014.

[2] Bitton, G. Wastewater Microbiology. Ed. John Wiley \& Sons, 3th. Edition, págs. 377 y 378. 2005.

[3] Brul, S., \& Klis, F. M. Mechanistic and mathematical inactivation studies of spoilage fungi. Fungal Genetics and Biology, vol. 27, págs. 199-208. 1999.

[4] Ogórek, R., Plaskowska, E., Kalinowska, K., Fornalczy, P., Misztal, A., \& Budziak, J. "The analysis of mycological air pollution in selected rooms of students hostels". Medical Mycology. Volumen 18, p. 201-210. 2011.

[5] Buchanan, B. "Sick Buildings, Sick Students". American School Board Journal, págs. 48-50. 2007.

[6] Stryjakowska, S. M., Piotraszewska, P. A., Szyszka, A., Nowicki, M. \& Filipiak, M. "Micriobiological quality of indoor air in university rooms". Polish Journal of Environmental Studies, Vol. 16, págs. 623-632. 2007.

[7] Medina, Luis; Tuozzo, Alihomar. Herrera, Judith; Perozo, Yelitza; González, Luis. "Estudio de hongos en bibliotecas de la Universidad de Carabobo-Valencia". Consejo de Desarrollo Científico y Humanístico. Universidad de Carabobo, Valencia, Venezuela. Vol. 3, N 1., 17p. 1999.

[8] Báez Flores, Maria Elena; Gaxiola Medina, Pável; Díaz Camacho, Sylvia Páz; Uribe Beltrán, Magdalena de Jesús; De la Cruz Otero, María del Carmen; Osuna Ramírez, Ignacio and Tiznado Hernández, Martín Ernesto. "Fungal Spore Concentrations in Indoor and Outdoor Air in University Libraries, and their Variations in Response to Changes in Meteorological Variables". International Journal of Environmental Health Research. 24(4):320-340. 2014.

[9] ASHRAE. "Ventilation for Acceptable Indoor Air Quality". ASHRAE Standard 62.1-2004. Atlanta, GA, American Society of Heating, Refrigerating and Air Conditioning Engineers. 2004.

[10] Koneman, E. W. y Roberts, G. D. Micología práctica de laboratorio. Editorial Médica Panamericana. Págs. 107-120. 1994. 